Supplement of Biogeosciences, 13, 3003-3019, 2016

http://www.biogeosciences.net/13/3003/2016/

doi:10.5194/bg-13-3003-2016-supplement

(C) Author(s) 2016. CC Attribution 3.0 License.

(c) (i)

Supplement of

\title{
Parametrization consequences of constraining soil organic matter models by total carbon and radiocarbon using long-term field data
}

Lorenzo Menichetti et al.

Correspondence to: L. Menichetti (ilmenichetti@gmail.com)

The copyright of individual parts of the supplement might differ from the CC-BY 3.0 licence. 
S1: Effect of the weighting parameter on the variance defining the probability distribution of the two data streams.

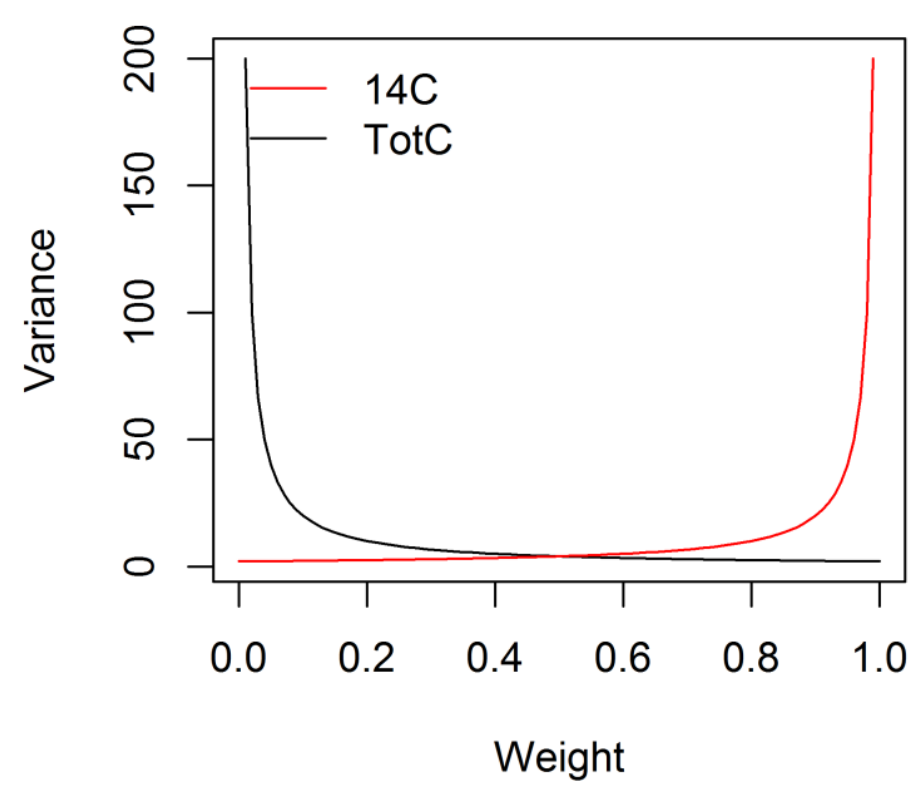


S2: Value (dimensionless) took by the climatic parameter $r$ (Eq. 9) over the simulation. The shaded area represents the parameter uncertainty.

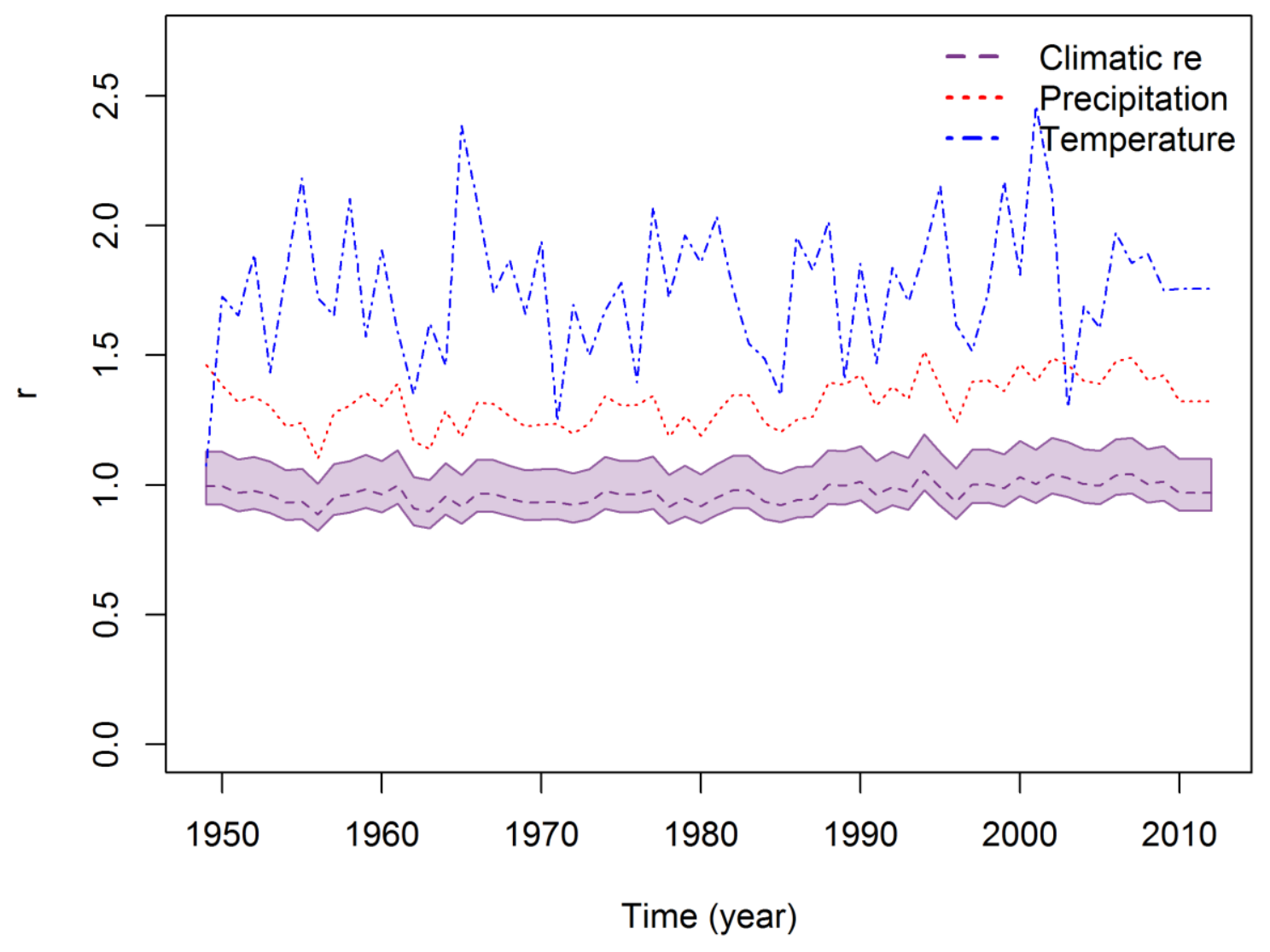


S3: Coefficient of variation of all the parameters (average) among all the three treatments for the five model structures with the variation of the relative weight of $\mathrm{SO}^{14} \mathrm{C}$ over total $\mathrm{C}$. In this scale 1 means only total $\mathrm{C}, \mathrm{O}$ means only $\mathrm{SO}^{14} \mathrm{C}$.

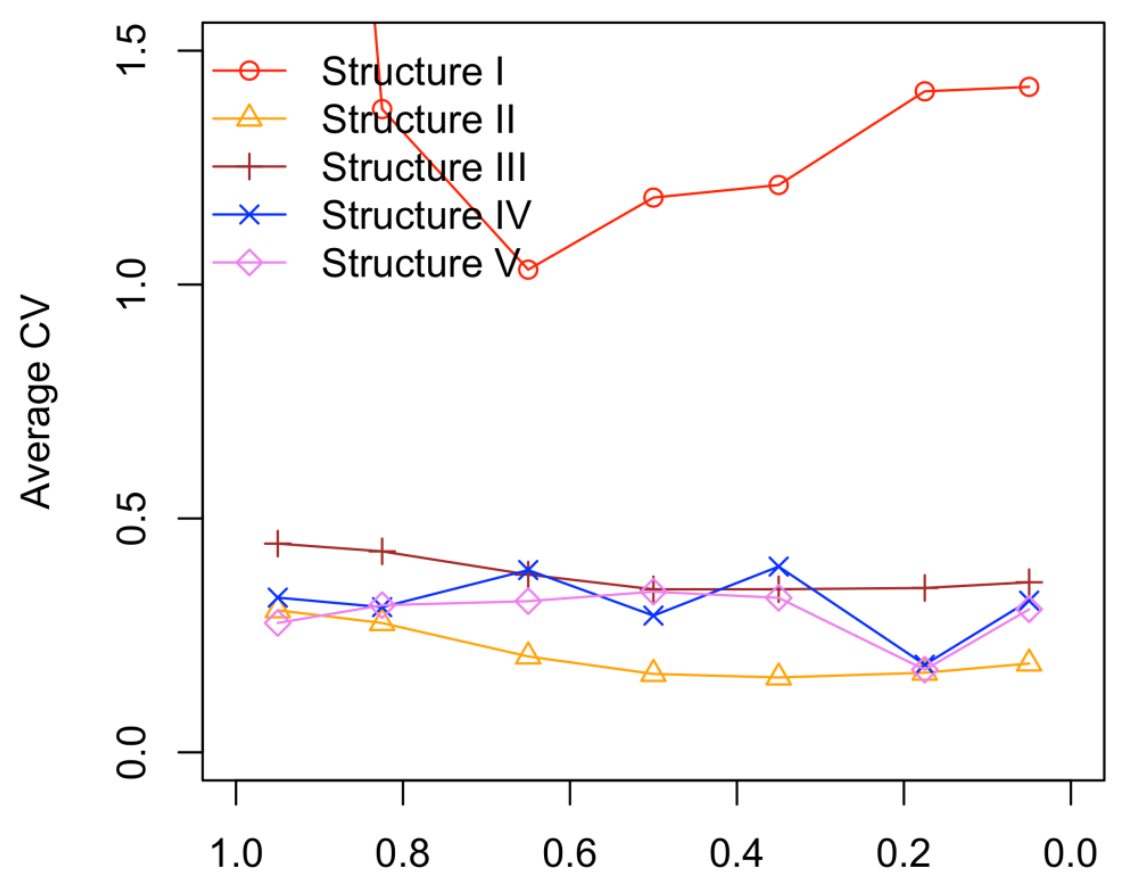

Weighting term 
S4: The posterior probability density (vertical axis) for the input error term (dimensionless, horizontal axis) for model structure I, II, II, IV and V.

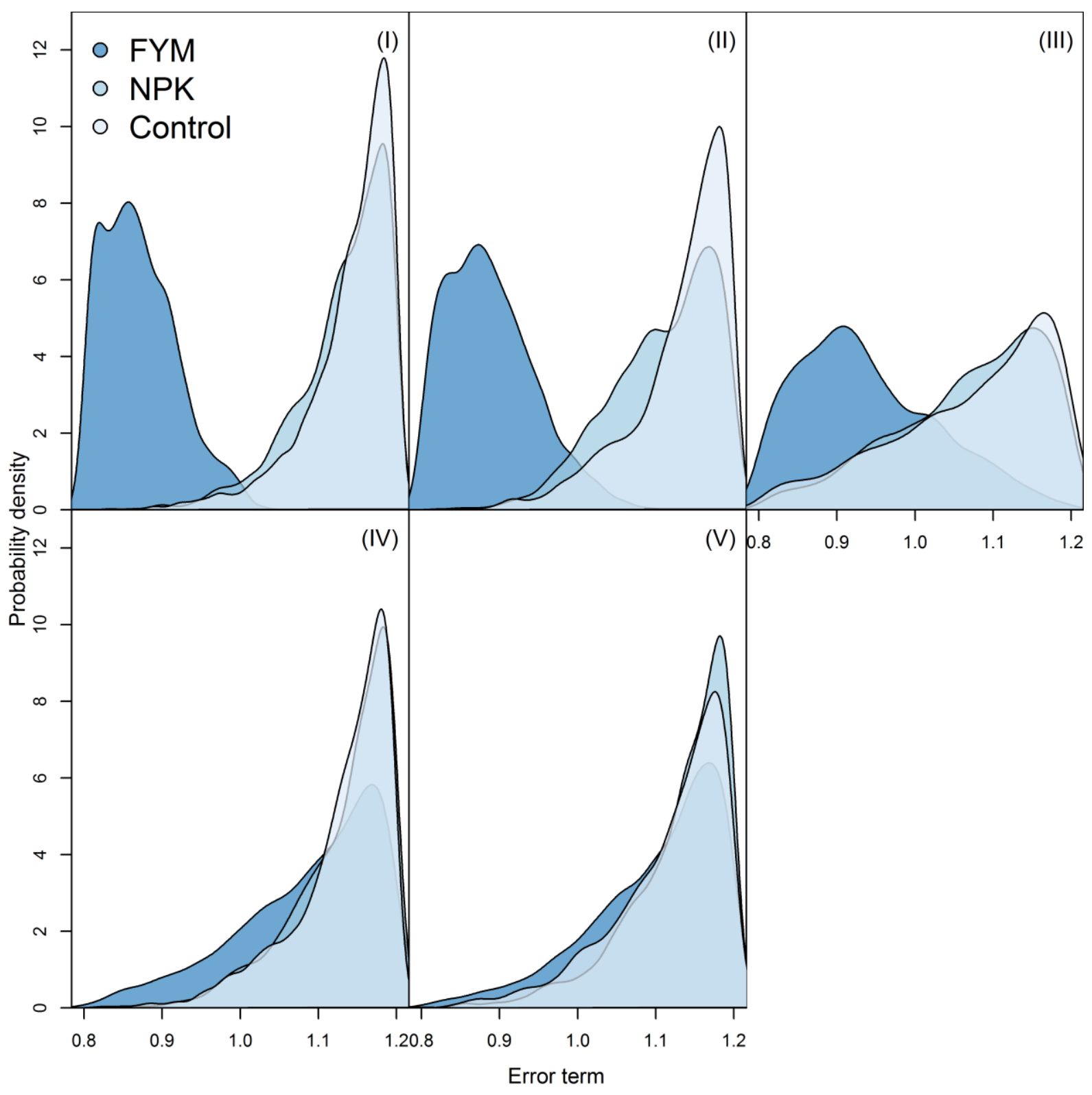


S5: Simulation of SOC pools in the ZOFE trial as described by model structure III, with weighting factor $=\mathbf{0 . 3 5}$. Error bars represent the measured (black) and estimated (dark grey) standard error of the measurements. SOC $(A, C, E)$ is in $\mathrm{Mg} \mathrm{ha}^{-1}$, while $\mathrm{SO}^{14} \mathrm{C}(\mathrm{B}, \mathrm{D}, \mathrm{F})$ is in pMC.

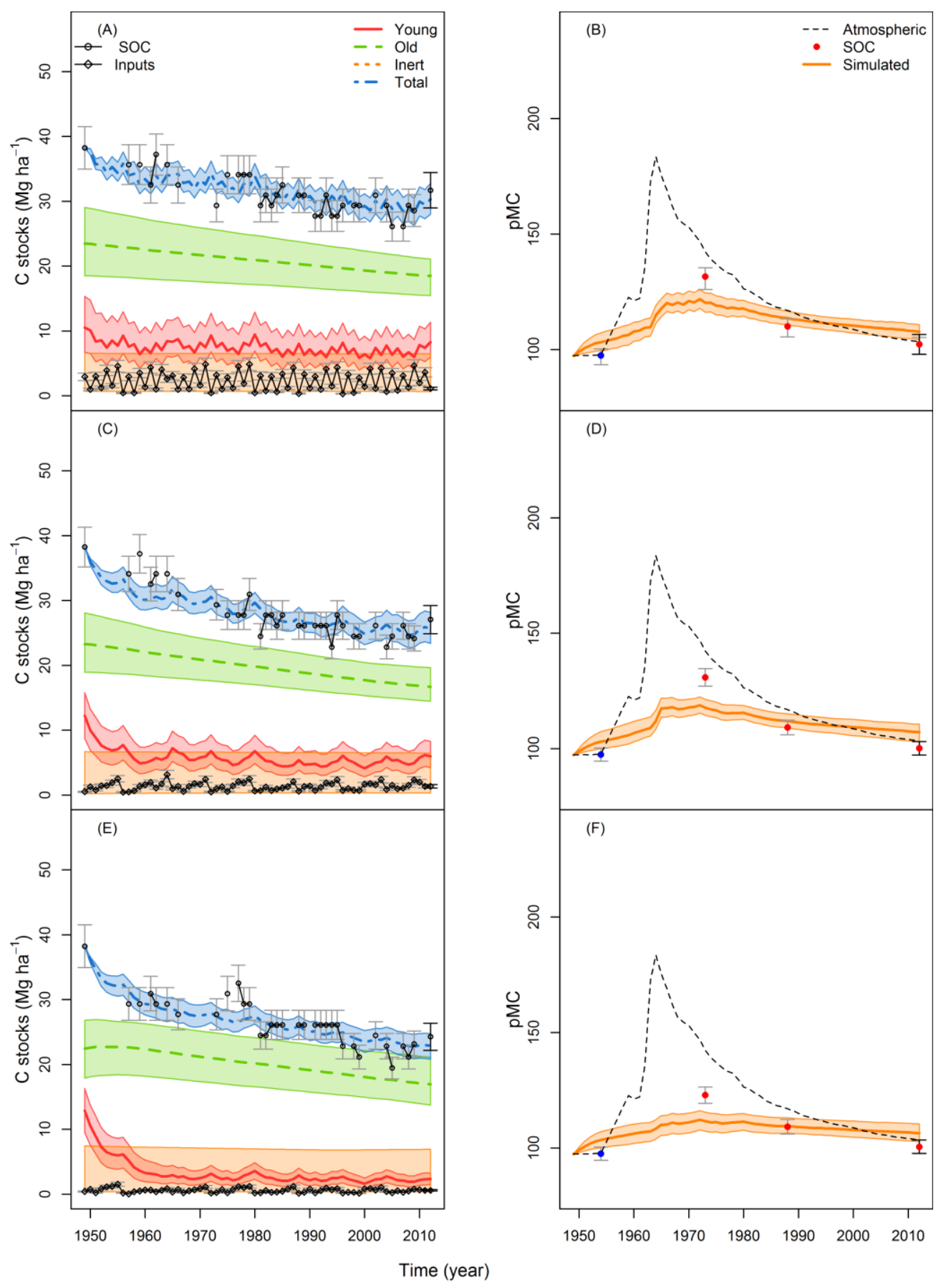


S6: Simulation of SOC pools in the ZOFE trial as described by model structure IV, with weighting factor $=0.35$. Error bars represent the measured (black) and estimated (dark grey) standard error of the measurements. SOC $(A, C, E)$ is in $\mathrm{Mg} \mathrm{ha}^{-1}$, while $\mathrm{SO}^{14} \mathrm{C}(\mathrm{B}, \mathrm{D}, \mathrm{F})$ is in pMC.

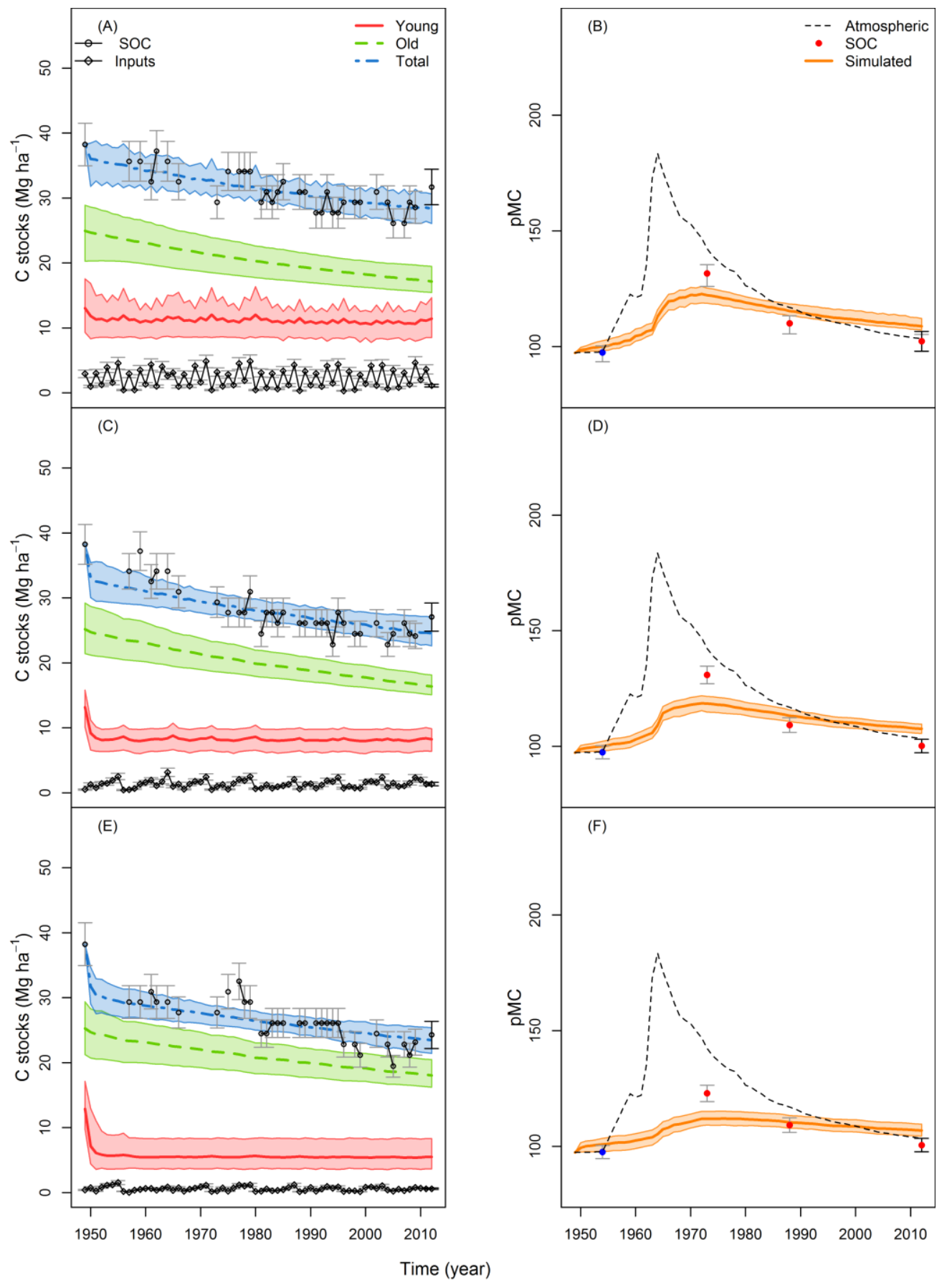


S7: Simulation of SOC pools in the ZOFE trial as described by model structure $\mathrm{V}$, with weighting factor $=0.35$. Error bars represent the measured (black) and estimated (dark grey) standard error of the measurements. SOC $(A, C, E)$ is in $\mathrm{Mg} \mathrm{ha}^{-1}$, while $\mathrm{SO}^{14} \mathrm{C}(\mathrm{B}, \mathrm{D}, \mathrm{F})$ is in $\mathrm{pMC}$.

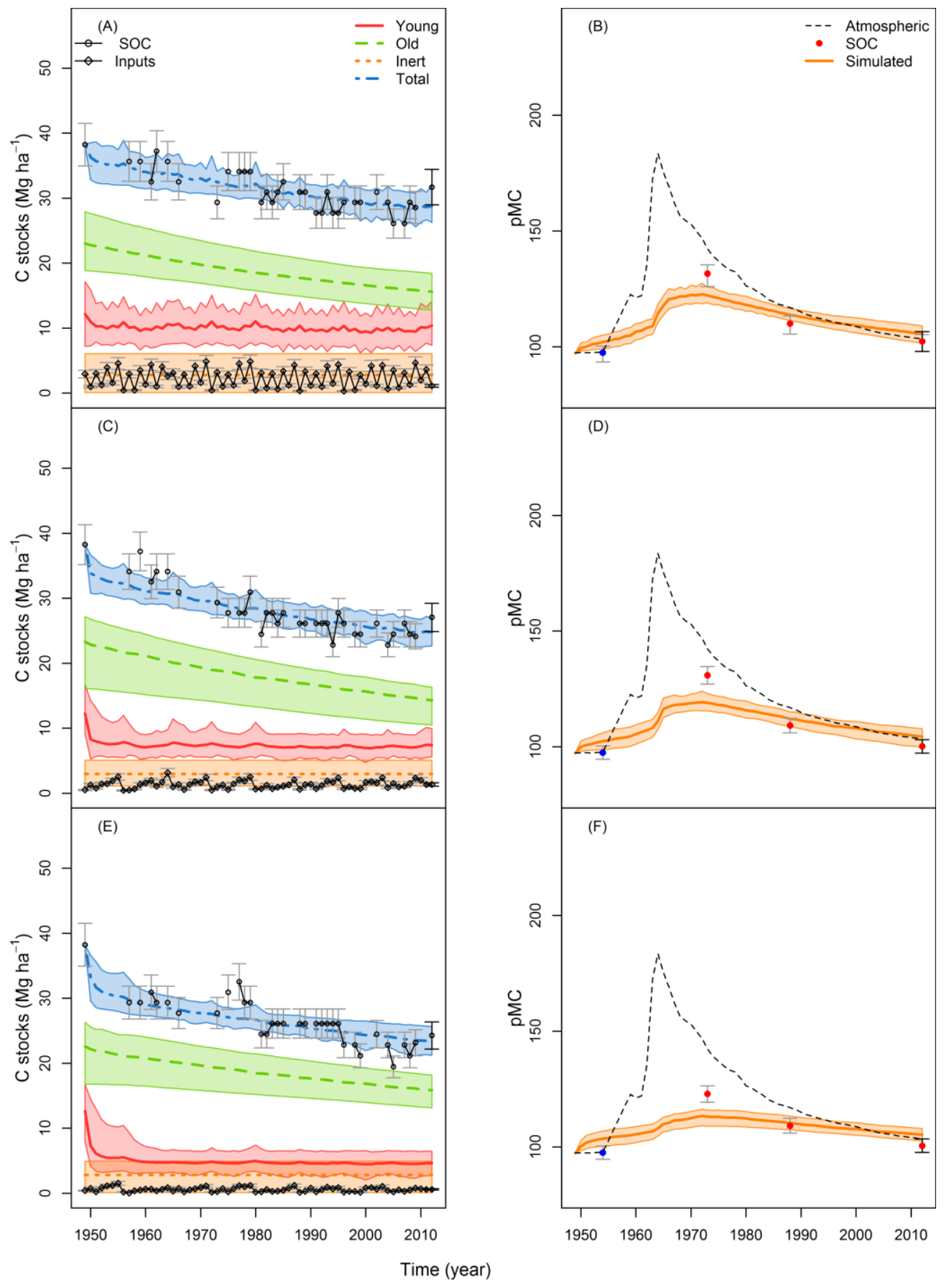


S8: Graphical abstract of model structure I

\section{Model \\ Structure I}

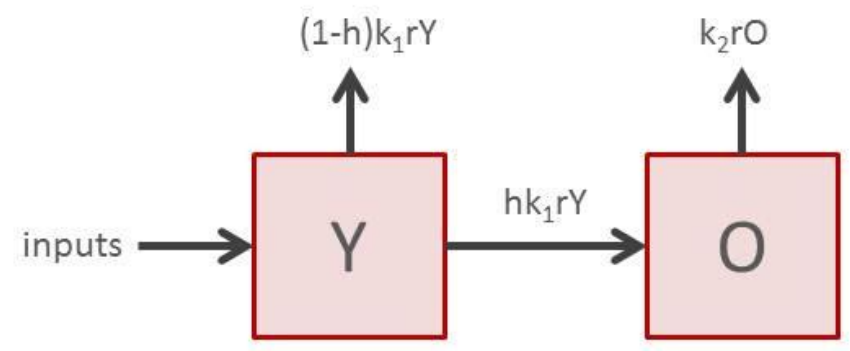


S9: Graphical abstract of model structure II

\section{Model \\ Structure II}
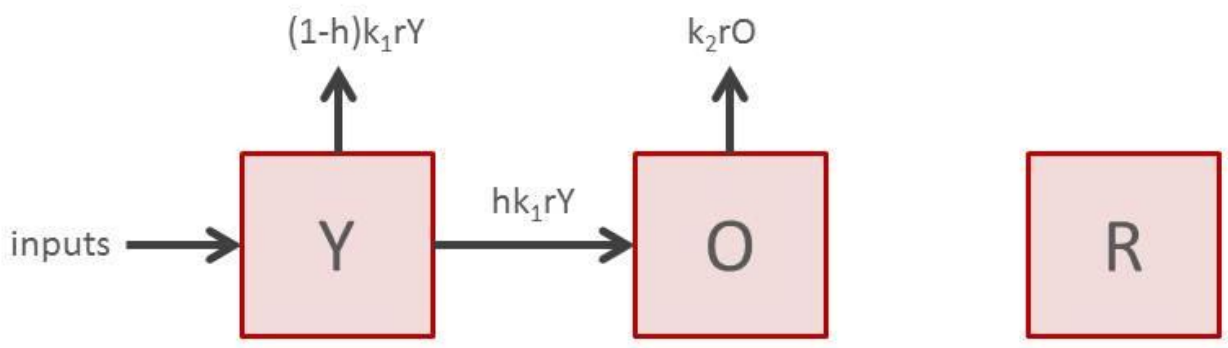
S10: Graphical abstract of model structure III

\section{Model \\ Structure III}

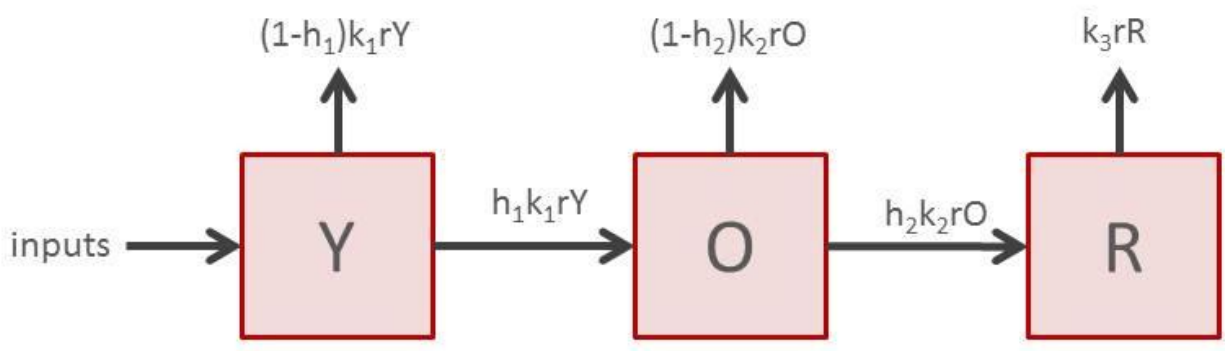


S11: Graphical abstract of model structure IV

\section{Model \\ Structure IV}




S12: Graphical abstract of model structure V

\section{Model Structure IV}
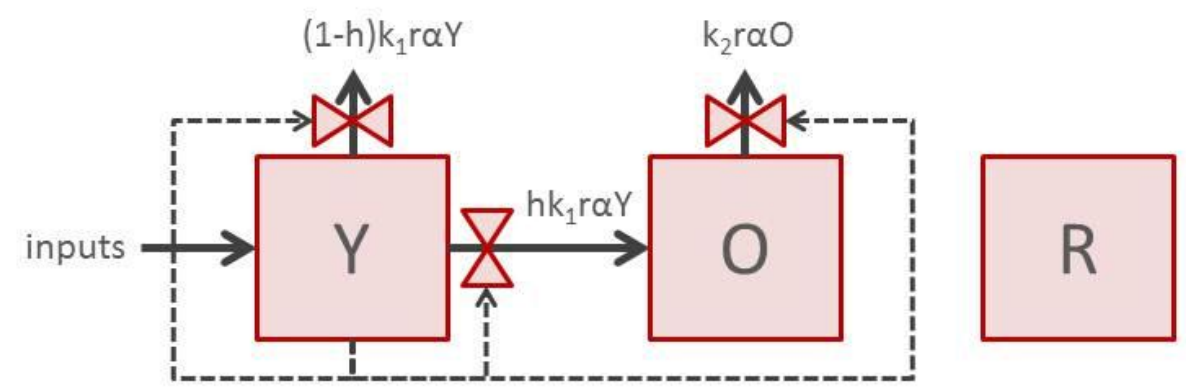